\title{
A VÍTIMA COMO FIGURA CONTEMPORÂNEA
}

\author{
Cynthia Sarti*
}

\begin{abstract}
Pensando sobre o sofrimento associado à violência, este texto busca levantar questões sobre a construção social e histórica da vítima e a extensão que essa figura adquire na sociedade contemporânea como legitimação moral de demandas sociais. A construção da vítima é pensada como forma de conferir reconhecimento social ao sofrimento, circunscrevendo-o e dandolhe inteligibilidade. O campo da saúde mental ocupa um lugar importante nesse processo, através da delimitação, pela Psiquiatria, do Transtorno de Estresse Pós-Traumático (TEPT) como referência para o tratamento de vítimas de violência, constituindo um foco privilegiado para essa reflexão. Trata-se de localizar a figura da vítima na lógica social que a engendra, indagando sobre a gramática dos conflitos que fundamentam sua construção e, assim, problematizar os usos que a noção de vítima enseja para legitimar ações sociais e políticas.

PALAVRAS-CHAVE: sofrimento, vítima, violência, reconhecimento, Transtorno de Estresse Pós-traumático (TEPT).
\end{abstract}

\section{INTRODUÇÃO}

Tendo a reflexão sobre o sofrimento associado à violência como pano de fundo, o objetivo deste texto é indagar a respeito da construção social e histórica da pessoa como vítima e pensar a extensão que essa figura adquire na sociedade contemporânea como forma de legitimação moral de demandas sociais. Essa reflexão surgiu de análises sobre a construção da violência como problema na área da saúde, tendo em vista o contexto em que se nomeia a violência, que agentes sociais a nomeiam, como e quem define a vítima e o agressor e como se expressa o sofrimento por quem a vivencia ou vivenciou. Essa perspectiva implicou problematizar, em particular, a noção de vítima, em torno da qual se articulam e desenham as políticas públicas de atendimento aos casos de violência na área da saúde. Essa noção constitui a razão

* Doutora em Antropologia pela Universidade de São Paulo (USP). Professora Titular da Universidade Federal de São Paulo (UNIFESP).

Universidade Federal de São Paulo, Campus Guarulhos. Estrada Caminho Velho, 333 - Bairro dos Pimentas. Cep: 07252-312 - Guarulhos, SP - Brasil. csarti@uol.com.br de ser das políticas públicas não só de atendimento aos vitimados, mas também de prevenção e combate à violência, que incluem as áreas do Direito e da Segurança Pública.

Analisamos anteriormente a entrada da questão da violência na área da saúde, em particular, as formas como se institui a atenção a esses casos e os agentes envolvidos, a partir da etnografia do atendimento em um hospital de emergências (Sarti; Barbosa; Suarez, 2006; Sarti, 2005). Entre outros fatores, essa entrada se associa ao impacto social e político dos movimentos sociais de cunho identitário, a partir da construção de suas reivindicações como direitos. Pela forte presença do movimento feminista nesse cenário, a perspectiva de gênero marcou significativamente a atenção à violência na área da saúde, que se delineou e se efetivou dentro do campo dos "direitos sexuais e reprodutivos” (Schraiber; d'Oliveira, 1999; Ávila, 2003). Desse panorama resultaram ações focalizadas de atendimento à violência na área da saúde, cuja estruturação e implantação responderam a demandas políticas de grupos específicos.

O impacto dos movimentos sociais de cu- 
nho identitário repercutiu nas esferas do Direito e da Saúde, que se articulam no processo de produção da vítima, fazendo com que o reconhecimento de um ato como violência e a atenção na área da saúde que daí decorre pressuponham a construção prévia de determinados grupos sociais, recortados por gênero e idade, como vulneráveis à violência, portanto como vítimas potenciais e detentores do direito a uma assistência específica, delimitando, assim, a abrangência do atendimento. A contrapartida dessa definição da violência - e da assistência que lhe é devida -é a desconsideração dessa vulnerabilidade em outros grupos sociais, quando não reconhecidos previamente como passíveis de sofrer atos violentos. Foi eloquente o caso, acompanhado pela equipe durante a pesquisa de campo no hospital, de um homem jovem que buscou atendimento frente à violência sexual por ele sofrida na ocasião de um assalto, segundo seu relato. Esse homem foi, inicialmente, dispensado, sob alegação de que o serviço de atendimento, integrado exclusivamente por ginecologistas e obstetras, era restrito a mulheres, sujeitos sociais entendidos como as vítimas, por excelência, de violência sexual (Krug et al., 2002). O foco de nossa análise do caso consistiu na perplexidade causada entre os profissionais quando o jovem voltou ao hospital para ser atendido, após sua busca e localização pela assistente social, naquilo que revelou das articulações sociais entre violência e gênero (Sarti; Barbosa; Suarez, 2006; Sarti, 2009).

Trata-se de problematizar o próprio processo de construção social da violência, pela invisibilidade em que permanece, na mesma medida em que se dá visibilidade à violência como fenômeno particular, e indagar sobre o lugar atribuído à vítima (e ao agressor) e o que a construção desse lugar diz não apenas da definição de prioridades e do desenho das políticas públicas relativas ao problema da violência, mas de formas contemporâneas de sociabilidade, entre as quais se circunscreve o sofrimento e o cuidado que lhe corresponde.

\section{VIOLÊNCIAS NA CONTEMPORANEIDADE}

Essa reflexão soma-se aos esforços, em curso na sociedade brasileira atual, de análise crítica das formas como a sociedade lida com a violência. Referimo-nos, de um lado, a experiências políticas, como a ditadura militar brasileira na segunda metade do século XX (1964-1985), e às formas de elaboração e reparação do sofrimento que implicou (Mezarobba, 2007) e, de outro, a ações e políticas públicas de combate à violência ou de atenção aos vitimados, em particular àquelas que respondem aos movimentos sociais de cunho identitário mencionados, que permitiram dar visibilidade a formas de violência antes não nomeadas como tal - das quais a violência contra a mulher e a criança e, mais recentemente, os idosos são casos emblemáticos -, de modo a garantir a efetivação dos direitos civis e sociais em termos de cidadania.

Esses esforços têm se voltado, em grande parte, para a revisão das instâncias jurídicas e das práticas do sistema de justiça criminal como modo privilegiado de combate à violência, com significativa produção nessa área. Zaluar (1999) já havia ressaltado que a análise da problemática da violência nas ciências sociais brasileiras privilegiou sua relação com a criminalidade e a justiça. As contribuições das pesquisas sobre violência - sobretudo aquelas sobre violência sexual, conjugal e doméstica - concentram-se na esfera jurídica e na área da segurança pública (Soares et al., 1996; Soares, 1999; Suarez; Bandeira, 1999; Brandão, 1999, 2006; Machado, 2002; Debert; Gregori, 2008). A extensão da questão da violência para o âmbito das políticas de saúde trouxe também para esse campo a discussão sobre a efetividade das ações de saúde como forma de consolidar direitos de cidadania, somando-se a elas iniciativas de investigação e ação (Minayo, 1994; Schraiber; d'Oliveira, 1999; Deslandes, 2002; Minayo; Souza, 2003; Villela; Monteiro, 2005, entre outros).

Os trabalhos desse campo temático evidenciam a complexidade da formulação de ações e políticas sociais em um cenário de novas configurações da violência, identificada, hoje, com aquilo 
que afeta existências singulares, pessoais ou coletivas, para além do que afeta a ordem social e política (Wieviorka, 1997, 2006), resultado do impacto de movimentos sociais em defesa dos direitos das "minorias" socialmente desfavorecidas, que contribuíram decisivamente para tirar da esfera privada e trazer à luz a questão da violência.

A noção de direitos, no entanto, ao se constituir em termos de direitos particulares, tal como é assumida por movimentos sociais de cunho identitário, exclui os outros - aqueles não reconhecidos na identidade em pauta - do âmbito de ações e reivindicações que dela derivam, evidenciando a intrincada relação entre particularidade e universalidade. Nessa perspectiva, reivindicada pelos movimentos identitários como necessária e estratégica para dar visibilidade ao que estava invisível, permanece o risco da cristalização de identidades particulares e do apagamento da tensão constitutiva da luta política por direitos em seu difícil equilíbrio entre o particular e o universal, terreno móvel, em constantes negociações na busca de administração social dos conflitos. ${ }^{1}$

O problema diz respeito à relação entre mim e o outro, na delimitação do que constitui culturalmente um grupo discriminado. Que lugar ocupa o outro nessa delimitação? Sobretudo nas situações de violência, há implicitamente a possibilidade de se associarem as características da vítima - e do agressor - a um determinado grupo social, essencializando-o e eludindo, assim, a complexa dimensão relacional da violência, em suas formas de espelhamentos e contrastes. Fixam-se identidades positivas, diante das quais a alteridade apare-

${ }^{1}$ Em relação à criação de delegacias especiais voltadas para minorias desfavorecidas, que respondem às ações da sociedade civil voltadas para segmentos específicos da população, Debert e Gregori (2008) mostram os inúmeros desafios criados a partir do pressuposto que orienta essas ações de que "a universalidade dos direitos só pode ser conquistada se a luta pela democratização da sociedade contemplar a particularidade das formas de opressão que caracterizam as experiências de cada um dos diferentes grupos desprivilegiados". As autoras citam os dilemas dos agentes policiais que, em face da criação de diversos tipos de delegacias de polícia (da criança e do adolescente, do idoso e dos crimes de racismo), precisam combinar a ética policial com a defesa dos interesses das minorias atendidas. "Esse desafio cria arenas de conflitos éticos, dando uma dinâmica específica ao cotidiano das delegacias, exigindo de seus agentes uma monumental criatividade”. (p.167) ce apenas como polo negativo. Obscurecem-se as "figuras da ambiguidade" que nos constituem, de que já havia falado Chauí (1985) em sua participação no debate sobre mulher e violência, quando a questão começava a emergir no cenário político brasileiro na década de 1980.

Os estudos sobre a violência contra a mulher, a partir do conceito de gênero, fizeram a crítica da vitimização, que supunha as mulheres como vítimas passivas da dominação masculina, apontando para as ambiguidades presentes nas relações intersubjetivas, ao mesmo tempo em que se afirmava - e continua a se afirmar - a relevância de situar a análise no contexto social das configurações de gênero (Pontes, 1986; Gregori, 1993; Grossi, 1994; Debert et al., 2006; Sarti: Barbosa; Suarez, 2006; Debert; Gregori, 2008). ${ }^{2}$ Análises que, além das vítimas, incluem os agressores entre os pesquisados evidenciam igualmente os mecanismos sociais pelos quais a violência contra a mulher atualiza e responde a padrões de relações de gênero e apontam os complexos jogos envolvidos e os deslocamentos de lugares nas relações violentas (Suarez; Bandeira, 1999; Machado, 2004). Outros estudos etnográficos mostram, ainda, os descompassos entre a perspectiva institucional e as razões que levam as mulheres a buscar assistência (Brandão, 1999, 2006; Soares, 1999), ou a construção do combate à violência a partir de uma perspectiva alheia ao mundo cultural ao qual se dirigem as ações (Simião, 2006).

Essas e outras discussões sobre ações coletivas e políticas públicas referidas às vítimas de violência evidenciam as distintas formas como a sociedade lida com a violência e com a administração dos conflitos na contemporaneidade. Dentro dessa discussão, buscamos problematizar a construção da pessoa como vítima: como é "produzida" a vítima, qual a perspectiva dos atores envol-

${ }^{2}$ Assim como se critica a tendência a esvaziar a articulação entre violência e gênero quando as Delegacias de Defesa da Mulher se voltam para a "violência doméstica” (Debert et al., 2006); ou, no campo da saúde, quando se privilegia a díade mãe e filho em detrimento da mulher na atenção primária em saúde, como no caso de experiências do Programa de Saúde da Família Villela e Monteiro (2005). 
vidos nessa produção e quais são seus modos de agência. Qual o contexto de emergência da noção de vítima, e que significados adquire em diferentes contextos?

Dentro da problemática do sofrimento associado à violência, a construção da pessoa como vítima no mundo contemporâneo é pensada como uma forma de conferir reconhecimento social ao sofrimento, circunscrevendo-o e dando-lhe inteligibilidade. $\mathrm{O}$ campo da saúde mental, em particular a Psiquiatria, ocupa um lugar preponderante nessa formulação ideológica (Eliacheff; Larivière, 2007; Fassin; Rechtman, 2002, 2007; Truchon, 2007; Fassin, 2004). Por essa razão, constitui um dos eixos privilegiados para essa reflexão.

\section{“DIAGNOSTICAR" A VIOLÊNCIA E CIRCUNS- CREVER A VÍTIMA}

Oalargamento do espaço social ocupado pela vítima no mundo atual está historicamente relacionado às melhores intenções. Daí a delicadeza da questão em pauta. ${ }^{3}$ No que se refere, pelo menos, ao mundo ocidental moderno, a identificação da vítima faz parte dos anseios de democracia e justiça, dentro do problema da consolidação dos direitos civis, sociais e políticos de cidadania. Remete à responsabilização social pelo sofrimento em face de catástrofes de várias ordens, desde guerras até acidentes naturais (terremotos, etc.) e à questão do reconhecimento como exigência básica do ser no mundo. ${ }^{4}$ Categoria histórica, seu significado define-se contextualmente, na dinâmica dos deslocamentos de lugares que marca as relações intersubjetivas, situadas em estruturas sociais de poder no interior das quais os conflitos são negoci-

${ }^{3}$ No registro da psicanálise, Koltai (2002) chama de "uma questão tão delicada" a transformação da vítima em metáfora da condição moderna, argumentando que "o sujeito moderno passa a não distinguir mais as fatalidades modificáveis das inexoráveis: a finitude e a morte" (p. 39)

${ }^{4}$ As formulações de Honneth $(2003,2006)$ sobre a gramática moral dos conflitos sociais e a luta por reconhecimento, supondo o nexo indissolúvel entre a integridade dos seres humanos e o assentimento por parte do outro, constitui referência para a linha de reflexão sobre a vítima aqui proposta. ados. Trata-se de compreender os mecanismos sociais e políticos de reconhecimento e nomeação da violência pelos quais a pessoa, na acepção de Mauss (1974b), é construída como vítima, a gramática moral que lhe dá a sustentação e, no plano do sujeito, a percepção subjetiva de si mesmo como tal.

Entre as entradas que possibilitam essa reflexão está a experiência de atrocidades, como a prática da tortura, durante o período da ditadura militar brasileira (1964-1985), momento singular na sociedade brasileira no qual, a partir das lutas pelos Direitos Humanos após a aprovação da Lei da anistia de 1979, a noção de vítima adquire uma lugar central. Por meio de tentativas de identificála, legitimou-se jurídica e socialmente a discussão das políticas de reparação dos danos, que, longe de estar resolvida, se situa no quadro geral dessas lutas não apenas no Brasil, mas nos demais países da América do Sul que viveram experiências de ditadura na segunda metade do século XX. Ao contrário da Argentina e do Chile, a questão do reconhecimento dos culpados, no caso do Brasil, reveste-se de ambiguidades, diante do investimento do Estado brasileiro na indenização das vítimas por compensação financeira, sem o empenho de buscar a verdade e a punição, como argumenta Mezarobba (2007).

Em sua origem, a noção contemporânea de vítima vincula-se precisamente às políticas de reparação frente às atrocidades das experiências de guerras (e, posteriormente, de regimes totalitários e autoritários), em particular o holocausto (Eliacheff; Larivière, 2007), dentro da perspectiva de internacionalização da questão do combate à violência, que transcende o espaço nacional, por inscrever-se na categoria de "crimes contra a humanidade”. A noção de vítima configura, assim, uma maneira de dar inteligibilidade ao sofrimento de segmentos sociais específicos, em contextos históricos precisos, que se produzem ou são produzidos como tal, conferindo legitimidade moral à suas reivindicações.

Como mostram Eliacheff e Larivière (2007), entretanto, a noção contemporânea de vítima adquire um novo estatuto a partir da definição, pela 
Psiquiatria, da categoria diagnóstica do Transtorno de Estresse Pós-Traumático (TEPT), com as formas terapêuticas que dela derivam. Resultante da orientação geral do DSM-III (a terceira versão do Diagnostic and Statistical Manual of Mental Disorders), publicado pela American Psychiatric Association em 1980, essa categoria diagnóstica constitui um dos suportes do tratamento das vítimas de violência na área da saúde mental na atualidade, constituindo-se em um importante articulador ideológico da produção da noção de vítima de violência no mundo contemporâneo.

Analisando a concepção de pessoa moderna, em suas relações com os saberes psiquiátricos, suas classificações e formas diagnósticas, Russo e Venâncio (2006) ressaltaram a "virada biológica" que se operou nos protocolos que orientam a prática psiquiátrica, da qual o DSM-III é emblemático, em contraposição à orientação anterior (DSM-II), na qual se observava a hegemonia da psicanálise na interpretação das perturbações mentais, o que implicava a afirmação da "dimensão moral do sujeito” sobre a dimensão física. Opera-se uma reconfiguração da concepção da pessoa, na qual se inscreve seu sofrimento. A análise dessa "voga biológica" e de seu impacto no "mundo psi" aponta para as formas em que emoção e sofrimento estão circunscritos na contemporaneidade pelos saberes que os reivindicam como objeto de sua verdade. ${ }^{5}$ Foram os psiquiatras, então, que, dispondo, por meio da categoria diagnóstica do TEPT, de ferramentas de identificação e qualificação da vítima, puderam universalizar essa noção, que se estendeu para qualquer gênero de perturbação (acidentes de carro, assaltos, catástrofes naturais, ferimentos por bala, etc.). Eliacheff e Larivière (2007) argumentam que passa a haver, então, uma relação de legitimidade moral entre uma categoria diagnóstica - o estresse pós-traumático - e uma categoria social-a vítima. Na mesma linha, Fassin e Rechtman (2007) argumentam que a noção de "traumatismo", designando uma realidade associ-

\footnotetext{
${ }^{5}$ Essa discussão foi comentada em recente revisão bibliográfica (Sarti, 2010b).
}

ada ao sentimento de empatia, invadiu o espaço moral das sociedades contemporâneas. Uma das repercussões socialmente relevantes do TEPT, segundo Eliacheff e Larivière (2007), é, assim, o esvaziamento do sentido histórico e contextual da figura da vítima, por sua aplicação irrestrita a qualquer tipo de vítima de violência, direta ou indiretamente, identificada pelos sintomas de "estresse", independentemente do lugar ocupado pelo sujeito no evento traumático, seja como vítima ou testemunha (ou, mesmo, algoz!). ${ }^{6}$

Na mesma linha de argumentação, Koltai (2002) fala da possibilidade de a vítima se tornar a representação dominante da subjetividade contemporânea, em uma sociedade de "reparação generalizada” (p.40), enquanto Fassin e Rechtman (2007) analisam a vítima como evidência da emergência de uma nova subjetividade política.

Tendo como eixo de suas preocupações os problemas colocados pela ascensão das vítimas nas sociedades democráticas, Truchon (2007) comenta, em ensaio bibliográfico, os autores contemporâneos que significativamente se debruçam sobre a emergência da vítima como figura reveladora de nossa época. A autora explora, em particular, os fatores que, segundo a literatura analisada, contribuem para fazer emergir a "vítima como herói contemporâneo”, citando Eliacheff e Larivière (2007). Destaca duas transformações sociais que explicam a mudança no estatuto da vítima e a passagem da vergonha que pesava sobre essa figura para seu reconhecimento recente por meio da noção de "traumatismo". De um lado, ressalta também a convergência entre especialistas da psicologia e da psiquiatria e os movimentos sociais e, de outro, as referidas transformações sociais pelas quais as categorias psiquiátricas se constituem em categorias morais, impondo um modelo médico sobre as formas de sofrimento associadas à experiência de guerra e de outras formas de violência (Eliacheff; Larivière, 2007; Fassin; Rechtman, 2007).

\footnotetext{
${ }^{6}$ Os autores chamam a atenção para as consequências da amplitude de aplicação do TEPT: excluída a consideração e análise do contexto, os algozes, porque estavam lá, podem tornar-se igualmente vítimas!
} 
Se a violência produz inquestionavelmente vítimas e elas têm o direito legítimo à reparação, a questão está em localizar a figura da vítima na lógica social que a engendra, indagando sobre os agentes envolvidos e a gramática dos conflitos que fundamentam sua construção e problematizando os usos que a noção de vítima enseja como forma de legitimação moral de demandas sociais e políticas.

\section{PENSAR A VÍTIMA E AS VIOLÊNCIAS}

Para situar teoricamente o sofrimento associado à violência e as formas como a sociedade lida com essa questão, impõe-se, na perspectiva antropológica, a necessidade de uma estratégia analítica que implique olhar para a totalidade, por meio dos recursos da etnografia, em sentido inverso ao da perspectiva objetivante das ciências biológicas - e, atualmente, a partir do DSM-3, também das psicológicas - com as quais o tema do sofrimento mantém uma necessária aproximação (Sarti, 2010a). Estamos falando de relações. Tratase, assim, de reintegrar e articular as partes para entender analiticamente as fronteiras a que foram confinados os fenômenos do sofrimento - e também o da violência-, fazendo dessas fronteiras, em si, o problema. Para não ser etnocêntrica, nem reproduzir o empiricismo dos saberes biológicos e psicológicos organicistas, que objetivam o que não é “objetivável”, a análise do sofrimento associado à violência supõe a referência ao sistema simbólico do qual se originam, por meio de um estranhamento radical de nossas próprias referências de sentido.

Na perspectiva de recuperar a totalidade, Augé (1986), em sua análise do corpo e da doença como objetos da análise antropológica, argumenta que há apenas uma antropologia, que se atribui distintos objetos empíricos (saúde, doença, religião, parentesco), sem se dividir em subdisciplinas. O autor pergunta se esses diferentes objetos da observação antropológica, ao término de seu esforço de construção, não constituíram um único objeto de análise. A questão é pertinente para a atualidade, no sentido de problematizar a tendência à especialização que assola também a antropologia, delimitando seu escopo, à maneira positivista, por objetos empíricos - antropologia da saúde, da ciência, das emoções, da dor, da violência, etc. -, naquilo que essa fragmentação das disciplinas tem empobrecido o debate teórico. ${ }^{7}$ A tendência a delimitar o objeto, que corresponde a demarcá-lo empiricamente, implica reificar as categorias com as quais a sociedade constrói o sofrimento (o corpo, a violência, etc.) em uma projeção da forma como o pensamento ocidental, científico e leigo as concebe, operando o que Duarte (1994) chamou de "uma espécie de enclausuramento epistemológico".

Quando se toma o sofrimento - físico ou moral - como objeto de reflexão na antropologia, não há como não prestar tributo a Marcel Mauss e à Escola Sociológica Francesa, que nos legaram o caminho teórico por onde pensar o corpo e os sentimentos como construções simbólicas, constituídos pelo significado que se configura na relação do indivíduo com o mundo social, processo de ordem cultural (Mauss, 1974b, 1979). A forma de manifestação do sofrimento precisa fazer sentido para o outro. Assim, não apenas sentir, mas expressar a dor e o sofrimento supõe códigos culturais que sancionam as formas de manifestação dos sentimentos. Vivenciados e expressos mediante formas instituídas, os sentimentos tornam-se socialmente inteligíveis. Constituem uma linguagem: "mais do que uma manifestação dos próprios sentimentos, é um modo de manifestá-los aos outros, pois assim é preciso fazer. Manifesta-se a si, exprimindo aos outros, por conta dos outros. É essencialmente uma ação simbólica”, na clássica citação de Mauss (1979, p. 153).

Nessa perspectiva, a figura da vítima constitui uma forma socialmente inteligível de expressar o sofrimento associadoà violência, legitimando deman-

\footnotetext{
${ }^{7}$ No ensaio bibliográfico referido, Truchon (2007) enfatiza, precisamente, as possibilidades da análise sob distintos ângulos, ressaltando o fato de as obras que analisa fornecerem tantas pistas a explorar sobre a emergência da vítima na contemporaneidade, "graças aos múltiplos pontos de vista que traz a pluralidade de campos disciplinares de seus autores" (p.220, tradução minha), entre os quais há sociólogos, antropólogos, além de um advogado, um psicanalista e um médico.
} 
das e ações sociais de reparação e cuidado. ${ }^{8}$ Se a experiência do sofrimento questiona, em si, o lugar do sujeito no mundo, como argumenta Le Breton (1995), o sofrimento associado à violência remete inelutavelmente à discussão moral. Para esse autor, toda dor envolve umgolpe moral, um questionamento da relação do indivíduo com o mundo.

$\mathrm{Na}$ análise das formas - linguagens - nas quais se expressa o sofrimento associado à violência, que a constitui como experiência, está em jogo precisamente essa tensão, de ordem moral, entre a dimensão subjetiva do sofrimento e as (im) possibilidades sociais de sua expressão. A expressão do sofrimento associado à violência não se separa dos constrangimentos que a provocaram, precisamente porque a violência se constitui em avesso da possibilidade de comunicação. Distinguindo conflito e violência, Wieviorka (2004) argumenta que a violência transcende o que é próprio das relações conflituosas. Ela é o limite do que não pode ser relacionado, comunicado. Constitui-se em um trauma, experiência que não é assimilável no momento em que ocorre, é indizível, inenarrável, porque não pode ser simbolizada. ${ }^{9} \mathrm{~A}$ dor da violência, como experiência traumática, pode, no entanto, ser ressignificada em momentos posteriores de elaboração, o que torna relevante o contexto de sua manifestação e o de sua elaboração, a partir do discurso de quem fala. Essa perspectiva implica discutir as condições de possibilidade de elaboração das experiências de dor e sofrimento, articulando aspectos subjetivos e contexto social e político, de forma a buscar o que permite falar ou o que faz silenciar; ou ainda, o que é permitido vir à tona e o que é deixado na sombra. Daí a importância da referência à questão da memória na análise

\footnotetext{
${ }^{8}$ A conhecida formulação de Foucault (1977), que contrapõe à "hipótese repressiva" a produção de discursos que circunscrevem o que pode ou não ser dito sobre a sexualidade, mantém-se como referência para pensar o problema da vítima como uma forma socialmente construída de circunscrever o sofrimento associado à violência. A vítima, assim, inscreve-se no discurso produzido sobre a violência na contemporaneidade.

${ }^{9}$ Convém lembrar, aqui, que é como experiência de trauma que se organiza a atenção à vítima na área da saúde mental, da qual a categoria diagnóstica mencionada de Transtorno de Estresse Pós-Traumático é o paradigma
} atual na Psiquiatria. do sofrimento associado à violência, voltando, nas ciências sociais, mais uma vez ao legado dos clássicos: dessa vez, Maurice Halbwachs ([1925], 1994; [1945], 1997), além da reflexão sobre o estatuto do testemunho, em particular no campo da literatura (Nestrovski; Seligman-Silva, 2000; Seligmann-Silva, 2003a, 2003b, 2005; Motta, 2004; Sarlo, 2005).

Como foi argumentado anteriormente, foi a emergência da questão dos direitos, na modernidade, que nomeou a violência e a qualificou como tal (Wieviorka, 1997), associando a categoria de vítima à de direitos. Para pensar a relação entre violência e direitos, cabe voltar (mais uma vez, um clássico) à formulação de Durkheim (1989), que permite entender a representação do corpo associado ao processo de individualização do sujeito na sociedade ocidental moderna. Como lembra Le Breton (2001), foi Durkheim quem colocou em evidência a necessidade de um "fator de individualização" na constituição do "eu", que foi consubstanciado no corpo ("É o corpo que desempenha esse papel”, p.331), permitindo distinguir um indivíduo do outro, marca do corpo na modernidade e delimitação da noção de direito individual que inaugura a modernidade ocidental e que passa a constituir um limite a partir do qual se pode definir a violência.

Se, como argumenta Le Breton (2001), os limites do corpo marcam a introdução na modernidade, pela noção de indivíduo que a ancora (Dumont, 1985), a crítica cultural da modernidade traz a reconfiguração desses limites no mundo contemporâneo. A relação entre indivíduo e sociedade é pensada a partir da fluidez dessa relação (Bauman, 2001), fluidez que estaria na base da indeterminação dos limites do corpo, limites entre mim e o outro, entre o sujeito interior e o mundo exterior (Haroche, 2008). Essa indeterminação de espaços e limites constituiria, em si, terreno propício à violência, tanto física quanto moral. Articula-se ao que Caldeira (2000) define como o "corpo incircunscrito", relacionado às formas como se instituíram os direitos de cidadania no Brasil, referindo-se à indefinição dos limites do corpo do outro, con- 
dição igualmente propícia ao abuso no exercício do poder e ao desrespeito aos direitos humanos.

Dada a generalização de formas violentas de agir, a violência aparece como um fenômeno difundido na sociedade contemporânea, ao mesmo tempo em que esse excesso põe em questão a própria conceituação do que é “violência”. Há violências, pois ela é contextual, em contraposição a qualquer noção essencialista de violência. Há lógicas culturais diversas a partir das quais a violência é qualificada como tal, cujo entendimento é fundamental para se pensar como superar a experiência da violência e não projetar uma lógica particular em políticas de combate à violência de um modo geral. ${ }^{10}$ Há, portanto, uma variabilidade na violência. É no terreno móvel das relações que podemos buscar sua compreensão.

Trata-se, aqui, não de resenhar as inúmeras teorias disponíveis sobre violência, mas de marcar a perspectiva antropológica que com elas dialoga pela análise, a partir de experiências etnográficas, da construção da violência como tal. Ou seja, não se parte de uma definição a priori do que constitui a violência, mas sua definição é referida ao sistema simbólico que a qualifica como tal, o que estabelece as condições de possibilidade de sua elaboração, que é tanto de ordem política, por dizer respeito à configuração do poder na sociedade, como cultural, por se inscrever na ordem simbólica.

Na medida em que a delimitação da vítima constitui a condição a partir da qual se formulam as políticas públicas e se desenham as formas de intervenção no combate à violência e na assistência às vítimas e supondo, como argumentado, que a violência é relacional e contextual, como, então, responder à questão aqui formulada: como se constrói a vítima?

A análise da construção da vítima supõe necessariamente o agressor e o contexto da violência, que permitem entender a lógica a partir da qual ela se manifesta e é qualificada como tal. Ser vítima não corresponde a um lugar fixo e, pelo caráter

${ }^{10}$ Entre os inúmeros exemplos etnográficos dessa afirmação estão: Clastres, 1990; [1980], 2004; Correa, 1983; Das 1995; Fonseca, 2000; Simião, 2006; Sarti, 2009. mutante da violência, seu lugar, assim como o do agressor, se desloca entre distintos sujeitos. ${ }^{11}$ Wieviorka (2004), para quem o discurso sobre a violência foi, durante muito tempo, alheio à vítima, argumenta, em sua busca de formular uma teoria da violência centrada no sujeito, que a reflexão sobre a violência deveria se inscrever em um triângulo, cujas bases sejam constituídas por: o protagonista da violência (o agressor), a vítima e a coletividade concernida. Para o autor, a partir daí, a discussão sobre a saída da violência (la sortie de la violence) ou sobre sua regressão (sa régression) deveria igualmente se inscrever nesse triângulo (p.46).

À consistente proposta pode-se agregar uma démarche. Pela forte conotação moral do discurso social sobre a violência, o empreendimento antropológico não pode prescindir de uma radicalidade como forma de garantir uma análise distanciada do contexto significativo no qual se inscrevem esses discursos. Sem adesão a um relativismo moral, trata-se de buscar, com base em experiências etnográficas, desconstruir os discursos contemporâneos sobre a violência - e o lugar atribuído à vítima nesses discursos -, buscando compreender a lógica na qual se inscrevem e empreender uma análise distanciada que permita abrir o caminho para uma política e uma intervenção social efetivas em seu enfrentamento.

(Recebido para publicação em novembro de 2010) (Aceito em fevereiro de 2011)

\section{REFERÊNCIAS}

ÁVILA, M.B. Direitos sexuais e reprodutivos: desafios para as políticas de saúde. Cadernos de Saúde Pública, São Paulo, v.19, supl. 2, p.465-469, 2003.

BAUMAN, Z. Modernidade líquida. Trad. Plínio Dentzien. Rio de Janeiro: Jorge Zahar, 2001.

${ }^{11}$ Entre os mecanismos de espelhamento que marcam as relações violentas, nas pesquisas que incluem os agressores entre os pesquisados, apontam-se experiências de violência por eles relatadas, tornando-os também "vítimas de violência”. Essa identificação foi analisada por Soares (1996), no capítulo intitulado "O inominável, nosso medo", e ressaltada como "uma das dimensões mais assustadoras da violência” (p. 59): a fusão que se opera entre vítima e agressor, instaurando uma simbiose. 
BRANDÃO, E.R. Renunciantes de direitos? A problemática do enfrentamento público da violência contra a mulher: o caso da Delegacia da Mulher. Physis: revista de Saúde Coletiva, Rio de Janeiro, v.16, n.2, p.207-231, 2006.

Violência conjugal e o recurso feminino à polícia. In: BRUSCHINI, C.; HOLLANDA, H.B. de (Org.) Horizontes plurais. São Paulo: Fundação Carlos Chagas/Editora 34,1999 . p.51-84.

CALDEIRA, T.P.R. Cidade de muros: crime, segregação e cidadania em São Paulo. Trad. Frank de Oliveira e Henrique Monteiro. São Paulo: EDUSP/Editora 34, 2000.

CHAUÍ, M. Participando do debate sobre mulher e violência. Perspectivas Antropológicas da Mulher, Rio de Janeiro, n.4, p.23-62, 1985.

CLASTRES, P. Arqueologia da violência: pesquisas de antropologia política. Trad. Paulo Neves. São Paulo: Cosac \& Naify, [1980] 2004.

Da tortura nas sociedades primitivas. In: A sociedade contra o Estado: pesquisas de antropologia política. 5.ed. Trad. Theo Santiago. Rio de Janeiro: Francisco Alves, 1990. p.123-31.

CORREA, M. Morte em família: representações jurídicas de papéis sexuais. Rio de Janeiro: Edições Graal, 1983.

DAS, V. Critical events: an anthropological perspective on contemporary India. New Delhi/Oxford: Oxford University Press, 1995.

DEBERT, G.G. et al. Gênero e distribuição da justiça: as delegacias de Defesa da Mulher e a construção das diferenças. Campinas: Núcleo de Estudos de Gênero - Pagu, 2006 (Coleção encontros).

; GREGORI, M.F. Violência e gênero: novas pro$\overline{\text { postas, }}$, velhos dilemas. Revista Brasileira de Ciências Sociais, São Paulo, v.23, n.66, p.165-211, 2008.

DESLANDES, S.F. Frágeis deuses: profissionais da emergência entre os danos da violência e a recriação da vida. Rio de Janeiro: Fiocruz, 2002.

DUARTE, L.F.D. Investigação antropológica sobre doença, sofrimento e perturbação: uma introdução. In: ; Leal, O.F. (Org.). Doença, sofrimento e perturbaÇão: perspectivas etnográficas. Rio de Janeiro: Editora FIOCRUZ, 1998. p.9-27.

DUMONT, L. O individualismo: uma perspectiva antropológica da ideologia moderna. Trad. Álvaro Cabral. Rio de Janeiro: Rocco, 1985.

DURKHEIM, E. As formas elementares da vida religiosa: o sistema totêmico na Austrália. Trad. Joaquim Pereira Neto. Revisão H. Dalbosco. São Paulo: Paulinas, [1912]. 1989.

ELIACHEFF, C.; LARIVIÈRE, D.S. Les temps des victimes. Paris: Albin Michel, 2007.

FASSIN, D. La cause des victimes. Les temps modernes, Paris, v.59, n.627, p.73-91, 2004.

; RECHTMAN, R. L'empire du traumatisme: enquete $\overline{\text { sur la }}$ condition de victime. Paris: Flammarion, 2007.

FASSIN, D.; RECHTMAN, R. (Orgs.). Traumatisme, victimologie et Psychiatrie humanitaire: nouvelles figures et nouvelles pratiques en santé mentale. Paris: Cresp/ Cesames, 2002.

FONSECA, C. Família, fofoca e honra: etnografia de relacões de gênero e violência em grupos populares. Porto Alegre: Editora da UFRGS, 2000.

GREGORI, M.F. Cenas e queixas: um estudo sobre mulheres, relações violentas e prática feminista. São Paulo: Paz e Terra/ANPOCS, 1993.

HALBWACHS, M. La mémoire collective. Paris: Albin Michel, 1997 [1945].
. Les cadres sociaux de la mémoire. Paris: Albin Michel, 1994 [1925].

HAROCHE, C. A condição sensível: formas e maneiras de sentir no Ocidente. Trad. Jacy Alves de Seixas e Vera Avellar Ribeiro. Rio de Janeiro: Contra Capa; 2008.

HONNETH, A. Luta por reconhecimento: a gramática moral dos conflitos sociais. Trad. Luiz Repa. São Paulo: Editora $34,2003$.

KOLTAI, C. Uma questão tão delicada. Psicologia Clínica, Rio de Janeiro, v.14, n.2, p.35-42, 2002.

LE BRETON, D. Antropologie du corps et modernité. 2.ed. Paris: PUF, 2001.

. Anthropologie de la douleur. Paris: Metailié, 1995.

KRUG, E.G. et al. (Ed.) Sexual violence. In: WORLD Report on Violence and Health. Geneva: World Health Organization, 2002. p.148-181.

MACHADO, L.Z. Masculinidades e violências: gênero e mal estar na sociedade contemporânea. In: SCHPUN, M.R. (Org.) As várias dimensões do masculino: traçando itinerários possíveis. São Paulo/Santa Cruz do Sul: Boitempo/ EDUNISC, 2004.

MAUSS, M. Uma categoria do espírito humano: a noção de pessoa, a noção do "Eu". In: Sociologia e antropologia. Trad. Mauro W.B. de Almeida e Lamberto Puccinelli. São Paulo: EPU/EDUSP, [1938] 1974a. v.1. p.207-239.

Efeito físico no indivíduo da ideia de morte sugerida pela coletividade. In:

São Paulo: EPU/EDUSP, [1926], 1974b. $\overline{\text { v.2. p.185-208. }}$

A expressão obrigatória dos sențimentos. In: OLIVEIRA, R.C. (Org.) Mauss. São Paulo: Ática, [1921]. 1979. p.147-53. (Grandes cientistas sociais, 11)

MEZAROBBA, G. O preço do esquecimento: as reparações pagas às vítimas do regime militar: uma comparação entre Brasil, Argentina e Chile. 2007. Tese (Doutorado em Ciência Política- Programa de Pós-Graduação em Ciência Política da Universidade de São Paulo, 2007.

MINAYO, M.C.S.; SOUZA, E.R. Violência sob o olhar da saúde: a infrapolítica da contemporaneidade brasileira. Rio de Janeiro: Ed. FIOCRUZ, 2003.

A violência social sob a perspectiva da saúde pública. Cadernos de Saúde Pública, Rio de Janeiro, v.10, supl.1, p.7-18, 1994.

MOTTA, L.T. Literatura e testemunho. In: Literatura e contracomunicação. São Paulo: Unimarco, 2004. p.35-75.

NESTROVSKI, A.; SELIGMAN-SILVA, M. (Org.) Catástrofe e representação. São Paulo: Escuta, 2000.

PONTES, H. Do palco aos bastidores: o SOS Mulher e as práticas feministas contemporâneas. 1986 Dissertação (Mestrado em Ciências Sociais) - Programa de Pós-Graduação e Ciências Sociais da Universidade Estadual de Campinas. São Paulo,1986.

RUSSO, J.; VENÂNCIO, A.T. Classificando as pessoas e suas perturbações: a revolução terminológica do DSM III. Revista Latinoamericana de Psicopatologia Fundamental, Perdizes,SP, v.9, n.3, p.460-483, 2006.

SARLO, B. Tiempo pasado. Cultura de la memória y giro subjetivo: una discusión. Buenos Aires: Siglo XXI, 2005.

SARTI, C.A.; BARBOSA, R.M.; SUAREZ, M.M. Violência e gênero: vítimas demarcadas. Physis: Revista de Saúde Coletiva, Rio de Janeiro, v.16, n.2, p. 167-183, 2006.

. Corpo e doença no trânsito de saberes. Revista Brasileira de Ciências Sociais, São Paulo, v.25, n.74, p.77-90, 2010a. 
Saúde e sofrimento. In: MARTINS, C.B.; DUARTE, L. F.D. (Coord.) Horizontes das Ciências Sociais brasileiras: antropologia. São Paulo: ANPOCS/ Barcarolla/Discurso Editorial; 2010b. p. 197-223.

Corpo, violência e saúde: a produção da vítima. Sexualidad, Salud y Sociedad: Revista Latinoamericana, Rio de Janeiro, v.1, n.1, p.89-103, 2009. Disponível em: www.e-public acoes.uerj.br/ojs/index.ph p/ SexualidadSaludy Sociedad/article/view/12/125.

$\mathrm{O}$ atendimento de emergência a corpos feridos por atos violentos. Physis: Revista de Saúde Coletiva, Rio de Janeiro, v.15, n.1, p.107-126, 2005.

SCHRAIBER, L.B.; d’OLIVEIRA, A.F.L.P. Violência contra mulheres: interfaces com a saúde. Interface - comunicação, saúde e educação, São Paulo, v.3, n.5, p. 13-26, 1999.

SELIGMANN-SILVA, M. (Org.) História, memória e literatura: o testemunho na era das catástrofes. Campinas: Ed. UNICAMP, 2003a.

ma. In:

Apresentação da questão: a literatura do trau(Org.) História, memória e literatura: testemunho na era das catástrofes. Campinas: Ed. UNICAMP, 2003b. p.45-58.

Literatura e trauma: um novo paradigma. In (Org.) O local da diferença: ensaios sobre memória, arte, literatura e tradução. São Paulo: Editora 34, 2005. p.63-80.

SIMIÃO, D.S. Representando corpo e violência: a invenção da "violência doméstica” em Timor Leste. Revista Brasileira de Ciências Sociais, Rio de Janeiro, v.21, n.61, p.133 145, 2006.
SOARES, B.M. Mulheres invisíveis: violência conjugal e novas políticas de segurança. Rio de Janeiro: Civilização Brasileira, 1999.

SOARES, L.E. et al. Violência e política no Rio de Janeiro. Rio de Janeiro: ISER/Relume Dumará, 1996.

SUÁREZ, M.; BANDEIRA, L. (Org.) Violência, gênero e crime no Distrito Federal. Brasília: Paralelo 15/Editora UnB, 1999.

TRUCHON, Karoline. Victimes et marchandeurs de mémoire (essai bibliographique). Anthropologie et Sociétés, v.31, n.2, p. 219-233, 2007. Disponível em: www. erudit.org/revue/as/2007/v31/n2/018691ar.pdf

WIEVIORKA, Michel. Violência hoje. Ciência e Saúde Coletiva, Rio de Janeiro, v.11, n.1, p.1147-1153, 2006.

Pour comprendre la violence: l'hipothèse du sujet. Sociedade e Estado, Brasília,DF, v.19, n.1, p.21-51, 2004 1997. Sociedade e Estado, Brasília,DF, v.9, n.1, p.5-41,

VILLELA, W.; MONTEIRO, S. (Org.) Gênero e saúde: Programa Saúde da Família em questão. Rio de Janeiro: Abrasco/UNFPA, 2005.

ZALUAR, A. Violência e crime. In: MICELI, S. (Org.) $O$ que ler na ciência social brasileira. São Paulo/Brasília: Sumaré-ANPOCS/CAPES, 1999. 


\section{THE VICTIM AS A CONTEMPORARY FIGURE}

\section{Cynthia Sarti}

Thinking about the suffering associated with violence, this text paper aims to raise questions about the social and historical construction of the victim and the extent that this figure takes on contemporary society as moral legitimacy of social demands. The construction of the victim is thought as a way of giving social recognition to suffering, circumscribing it and giving it intelligibility. The field of mental health has an important place in this process, through the delimitation, by the Psychiatry, of Post Traumatic Stress Disorder (PTSD) as a reference for the treatment of victims of violence, constituting a privileged focus for this reflection. One tries to locate the figure of the victim in the social logic that engenders it, inquiring about the grammar of the conflicts that underlie its construction and thus questioning the uses to which the notion of victim gives rise to legitimate social and political action.

KEYWORDS: suffering, victim, violence, recognition, Post Traumatic Stress Disorder (PTSD).

\section{LA VICTIME COMME FIGURE CONTEMPORAINE}

\section{Cynthia Sarti}

À partir d'une réflexion sur la souffrance associée à la violence, ce texte veut lever des questions sur la construction historique et sociale de la victime ainsi que sur l'étendue que cette figure acquiert dans la société contemporaine comme une légitimation morale de demandes sociales. La construction de la victime est pensée comme une manière d'attribuer une reconnaissance sociale à la souffrance en la circonscrevant et en lui donnant une intelligibilité. Le domaine de la santé mentale occupe une place importante dans ce processus vu la délimitation faite par la Psychiatrie du Trouble de Stress post traumatique (TSPT) pris comme référence pour le traitement des victimes de la violence, élément essentiel de notre réflexion. Il s'agit de situer la figure de la victime dans la logique sociale qui l'engendre en prenant connaissance de la grammaire des conflits qui sont à la base de sa construction afin de problématiser les usages que la notion de victime produit pour légitimer des actions sociales et politiques.

MotS-CLÉS: souffrance, victime, violence, reconnaissance, Troubles du Stress Post-traumatique (TSPT).

Cynthia Sarti - Doutora em Antropologia. Professora Titular da Universidade Federal de São Paulo (UNIFESP). Livre-Docente pelo Departamento de Medicina Preventiva da Universidade Federal de São Paulo. Integra atualmente o Departamento de Ciências Sociais da Escola de Filosofia, Letras e Ciências Humanas da UNIFESP/Campus Guarulhos, recentemente criada pelo Novo Estatuto desta universidade. Atua na área de Antropologia, com ênfase nos seguintes temas: dor, sofrimento e violência; corpo, saúde e doença; moralidade; família; gênero. 